University of Nebraska - Lincoln

DigitalCommons@University of Nebraska - Lincoln

Faculty Publications from the Department of Electrical \& Computer Engineering, Department Electrical and Computer Engineering

2002

\title{
Shape-based Change Detection and Information Mining in Remote Sensing
}

Jiang Li

University of Nebraska-Lincoln

Ram M. Narayanan

University of Nebraska-Lincoln

Follow this and additional works at: https://digitalcommons.unl.edu/electricalengineeringfacpub

Part of the Electrical and Computer Engineering Commons

Li, Jiang and Narayanan, Ram M., "Shape-based Change Detection and Information Mining in Remote Sensing" (2002). Faculty Publications from the Department of Electrical and Computer Engineering. 153. https://digitalcommons.unl.edu/electricalengineeringfacpub/153

This Article is brought to you for free and open access by the Electrical \& Computer Engineering, Department of at DigitalCommons@University of Nebraska - Lincoln. It has been accepted for inclusion in Faculty Publications from the Department of Electrical and Computer Engineering by an authorized administrator of DigitalCommons@University of Nebraska - Lincoln. 


\title{
Shape-based Change Detection and Information Mining in Remote Sensing
}

\author{
Jiang Li and Ram M. Narayanan \\ Environmental Remote Sensing Laboratory, Center for Electro-Optics, \\ Department of Electrical Engineering, University of Nebraska-Lincoln, Lincoln, NE 68588-0511 \\ Tel: (402) 472-5141, FAX: (402) 472-4732, Email: ram@doppler.unl.edu
}

\begin{abstract}
Change detection is an important application of remote sensing. This paper presents our approach to retrieve and represent interesting shapes in the remotely sensed imagery using supervised classification, edge detection, and polygonal approximation techniques, and to compare the shape similarity by a computationally efficient metric. The experiments were conducted on a time series of calibrated and registered Landsat MSS images, covering the scene of the lakes at the western Nebraska. The results show the effectiveness of the shape-based change detection approach, which is potentially useful for specific applications such as the study of the lake change response to short or long term climatic variation and flood or drought monitoring.
\end{abstract}

\section{INTRODUCTION}

Change detection is an important application of remote sensing. Most of the traditional change detection techniques are pixel-based by means of the confusion matrix. Shape retrieval and representation have not been considered in remote sensing as widely as it has in other pattern recognition applications. However, shapes such as those of rectangular or circular fields in agriculture and lakes with occluded boundaries can be quite well identified from the remotely sensed imagery even at relatively coarse spatial resolution.

Shape retrieval can be carried out using template edge detection techniques, while for representation, there are some popular methods including the adoption of shape factors, moments of area, and Fourier transforms of shape boundaries. Other aspects that play an important role in the algorithmic solutions to shape representation are the approximation of shapes, the measurement of shape similarity, and the organization of shapes into search structures. An overview of the state of art in shape analysis, classification, and similarity measure is given in [1] and [2].

This paper presents our approach to retrieve and represent interesting shapes in the remotely sensed imagery using classification followed by edge detection, contour tracing, and polygonal approximation techniques [3], and to compare the similarity between shapes using a metric [4]. The experiments were conducted on Landsat MSS images and focused on the change detection of the lakes at the western Nebraska. The retrieved shape vectors with corresponding similarity measures are potentially useful for specific applications such as the study of the lake change response to short or long term climatic variation and flood or drought monitoring.

\section{SUPERVISED CLASSIFICATION}

One of the requirements to perform change detection using remotely sensed data is to identify land cover classes of interest to be monitored. Supervised classification is preferred in this study since we are concerned with the changes to the lakes for which many training data sets are available. The image set consists of 64 calibrated and registered Landsat MSS images with a $79 \mathrm{~m}$ spatial resolution, covering the scene of lakes at the western Nebraska and encompassing the period from 1973 to 1986 . A sample RGB combined image is shown in Fig. 1.

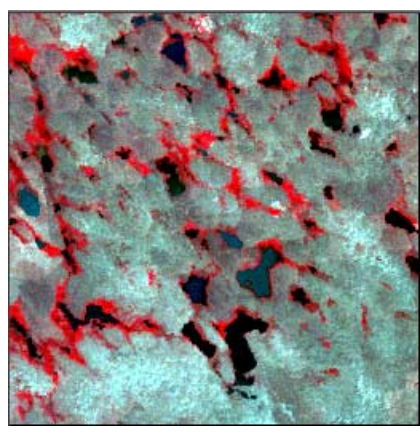

Fig. 1. Landsat MSS image.
Fig. 2. Classified image.

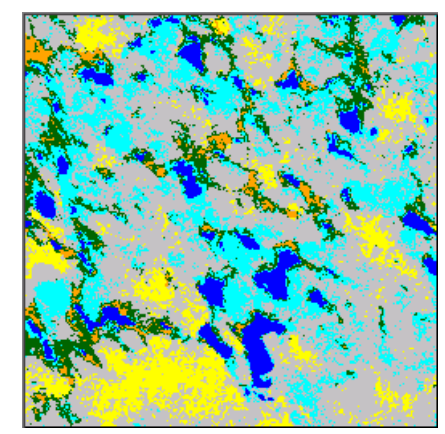

USGS Land Use / Land Cover Classification System was used to identify six classes shown in Table 1 . The colors in the left column indicate the training signatures in the original image, while the colors in the right column indicate the labeled classes in classified image as shown in Fig. 2.

TABLE 1. SIX LAND COVER CLASSES IDENTIFIED

\begin{tabular}{|l|l|l|}
\hline & Water & \\
\hline & Wetland & \\
\hline & Barren Land & \\
\hline & Rangeland & \\
\hline & Forest Land & \\
\hline & Agricultural Land & \\
\hline
\end{tabular}

We implemented a Support Vector Machine classifier with Radial Basis Function (RBF) kernel based on the SVMLIB library [5], which is computationally simple and can result in accuracy better than other more computationally intensive rules like Maximum Likelihood rule. Training data were sampled using an 8-neighborhood region growing approach by simultaneously setting the spatial constraints including the maximum area of the region and the maximum distance from the seed pixel, and spectral Euclidean distance, which refers to those pixels whose spectral reflectance is within a certain distance from the mean of the seed pixel. 


\section{EDGE DETECTION}

The now widely accepted method for edge detection consists of derivative filtering, which detects transitions or changes in gray levels in the image. Since it is inherently difficult to extend differential methods to multi-band images by computing the gradient of the vector field [6], in this study, edge detectors are applied to the classified images. The lake of interest, e.g. Crescent Lake, was first masked in the classified images as shown in Fig. 3. Then a set of linear edge detection templates were applied to this binary image to get a continuous boundary contour as shown in Fig. 4. A $3 \times 3$ window $W$ centered over the pixel located at $(i, j)$ was defined. Four convolution templates for detecting edges in four directions, i.e., North-South, West-East, NortheastSouthwest, and Northwest-Southeast, are shown in Table 2.

TABLE 2. LINEAR EDGE DETECTION TEMPLATES

\begin{tabular}{|c|c|c|c|c|c|c|c|c|c|c|c|}
\hline \multicolumn{3}{|c|}{$\mathrm{N}-\mathrm{S}$} & \multicolumn{3}{|c|}{ W-E } & \multicolumn{3}{|c|}{ NE-SW } & \multicolumn{3}{|c|}{ NW-SE } \\
\hline-1 & -1 & -1 & -1 & 0 & +1 & 0 & +1 & +1 & +1 & +1 & 0 \\
\hline 0 & 0 & 0 & -1 & 0 & +1 & -1 & 0 & +1 & +1 & 0 & -1 \\
\hline+1 & +1 & +1 & -1 & 0 & +1 & -1 & -1 & 0 & 0 & -1 & -1 \\
\hline
\end{tabular}

The new value at $(i, j)$ was computed using $(1)$, where $W$ represents the window at $(i, j), T_{k}$ is the $k$ th template, and $\varphi$ is an appropriate threshold value. Results show that all the boundaries of lakes are closed and most of the skeletons are single pixel wide with very few spur pixels. Therefore, thinning and linking operations were not applied.

$$
f(i, j)=\left\{\begin{array}{l}
1, \max _{k}\left(\left|\sum_{i, j} \frac{W \times T_{k}}{3}\right|\right) \geq \varphi \\
0, \max _{k}\left(\left|\sum_{i, j} \frac{W \times T_{k}}{3}\right|\right)<\varphi
\end{array}\right.
$$
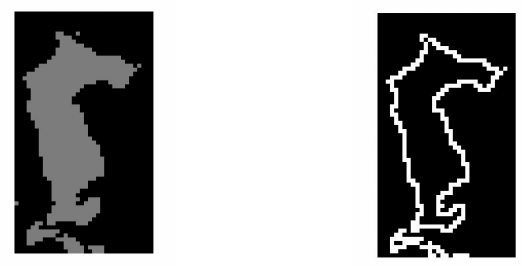

Fig. 3. Masked Crescent Lake. Fig. 4. Detected boundary.

\section{CONTOUR TRACing And POLYGOnAL APPROXIMATION}

In order to characterize the contour in vector format, we developed an efficient algorithm to track the shape boundary in a given order and to simultaneously approximate it by a polygon. It can tolerate double width lines and prune the spur pixels from the skeletonized image.

\section{A. Contour Tracing}

The tracing starts at the left extremity of the boundary and works around it in an 8-connective way. It terminates when coming back to the starting point. This is guaranteed because the boundary of the lake is occluded. To prune spur pixels along the tracing path, a one-step look-ahead strategy was adopted as shown in Table 3. Suppose $N$ is the current position and $N+1$ is the next possible position, i.e., the adjacent non-zero value pixel. The pixel at $N$ was first masked with zero. Then if all the neighbor pixels of $N+1$ have a zero value, pixel at the $N+1$ is a spur pixel. The algorithm masks it with zero and searches in another direction. Fig. 5 and 6 show two examples of the points' coordinates representing the contour of Crescent Lake.

TABLE 3. SPUR PIXELS PRUNING

\begin{tabular}{|c|c|c|c|c|c|c|c|c|c|c|c|}
\hline \multicolumn{3}{|c|}{ South } & \multicolumn{3}{|c|}{ East } & \multicolumn{3}{|c|}{ Southeast } & \multicolumn{3}{|c|}{ North } \\
\hline $\mathrm{X}$ & $\mathrm{N}$ & $\mathrm{X}$ & $\mathrm{X}$ & ? & $?$ & $\mathrm{~N}$ & 0 & $?$ & $?$ & $?$ & $?$ \\
\hline$?$ & $\mathrm{~N}+1$ & $?$ & $\mathrm{~N}$ & $\mathrm{~N}+1$ & $?$ & 0 & $\mathrm{~N}+1$ & $?$ & $?$ & $\mathrm{~N}+1$ & $?$ \\
\hline 0 & ? & $?$ & 0 & ? & ? & $?$ & ? & ? & $\mathrm{X}$ & $\mathrm{N}$ & 0 \\
\hline \multicolumn{3}{|c|}{ Northeast } & \multicolumn{3}{|c|}{ West } & \multicolumn{3}{|c|}{ Northwest } & \multicolumn{3}{|c|}{ Southwest } \\
\hline$?$ & $?$ & $?$ & $?$ & $?$ & 0 & $?$ & $?$ & $?$ & $?$ & 0 & $\mathrm{~N}$ \\
\hline 0 & $\mathrm{~N}+1$ & $?$ & $?$ & $\mathrm{~N}+1$ & $\mathrm{~N}$ & $?$ & $\mathrm{~N}+1$ & 0 & ? & $\mathrm{N}+1$ & 0 \\
\hline $\mathrm{N}$ & 0 & ? & $?$ & ? & 0 & $?$ & 0 & $\mathrm{~N}$ & ? & ? & ? \\
\hline
\end{tabular}
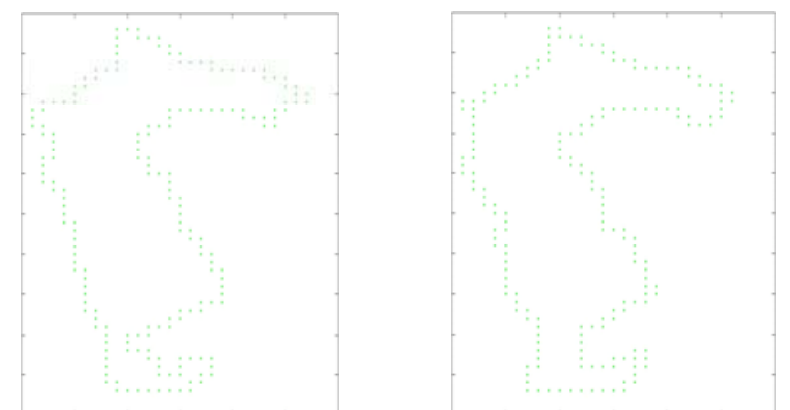

Fig. 5. Edge coordinates in May 1983. Fig. 6. Edge coordinates in April 1984.

\section{B. Polygonal Approximation}

To facilitate measurement of the shape similarity discussed in the next section and reduce the length of the vectors need to be stored, a piecewise linear polygonal approximation is applied during the tracing process. We modified the algorithm that runs in time $O(n)$ [3] so that it can take nontime series data.

Given a sequence of points $S$ and an user defined error threshold $\Psi$, it finds a piecewise linear function $f$ composed of line segments, such that the end points of each piece of $f$ occurs in $S$ and satisfies (2). As shown in Fig. 7, it tries to extend each piece until it cannot because the upper line $U_{b, e}$ becomes lower than the lower line $L_{b, e}$. Two samples are shown as Fig. 8 and 9 respectively.

$$
\left|f\left(x_{i}\right)-y_{i}\right| \leq \Psi, \forall \quad\left(x_{i}, y_{i}\right) \in S .
$$

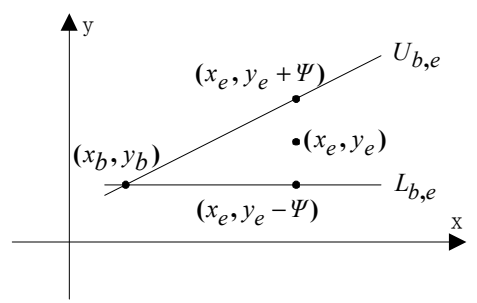

Fig. 7. The upper and lower lines. 


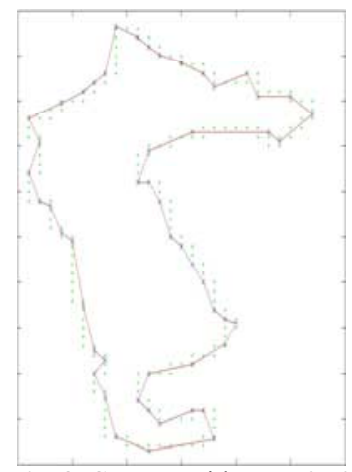

Fig. 8. Contour with $\Psi=0.50$

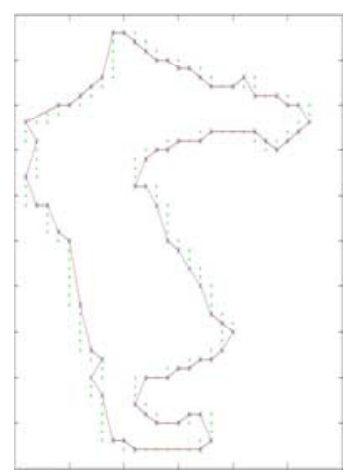

Fig. 9. Contour with $\Psi=0.25$.

\section{Shape Similarity Measure and Query}

An efficiently computable metric was used to measure the similarity between the shapes. This metric matches our intuitive notions of shape resemblance, i.e. similar to those that a person might provide. The computation complexity is $O(m n \log m n)$ where $m$ is the number of vertices in one polygon and $n$ is that number of vertices in the other. The detailed representation of polygons using turning function and corresponding distance function were presented in [4] and briefly described below.

The boundary of a polygon $\boldsymbol{A}$ can be represented using a turning function $\Theta_{A}(s)$, which is the cumulative angle of the counterclockwise tangent as a function of the arc length $s$, measured from some reference point $\boldsymbol{O}$ on $\boldsymbol{A}$ 's boundary. Assume each polygon is rescaled so that the total perimeter length is 1 ; hence, $\Theta_{A}$ is a function from $[0,1]$ to $R$. Consider two polygons $\boldsymbol{A}$ and $\boldsymbol{B}$ and their associated turning functions $\Theta_{A}(s)$ and $\Theta_{B}(s)$. The degree to which $\boldsymbol{A}$ and $\boldsymbol{B}$ are similar is measured by taking the distance between the functions $\Theta_{A}(s)$ and $\Theta_{B}(s)$ according to the metric on function spaces. $L_{P}$ distance between $\boldsymbol{A}$ and $\boldsymbol{B}$ is defined as

$$
\delta_{P}(A, B)=\left\|\Theta_{A}-\Theta_{B}\right\|_{P}=\left(\int_{0}^{1}\left|\Theta_{A}(s)-\Theta_{B}(s)\right|^{P} d s\right)^{\frac{1}{P}},
$$

where \|\|$_{P}$ denotes the $L_{P}$ norm [4], and $P=2$ in our case. Fig. 10 shows the inter-annual relative surface-area fluctuations with the corresponding similarity metric (compare to May 1986) of Crescent Lake, while Fig. 11 shows its seasonal variability (sequential change) in 1983.

The shape vectors of all the lakes in the study area with spatial and temporal information were stored in an objectoriented database. We calculated the coefficient of variation (CV) [7] for each of the lake in the study area, where

$$
C V=(\text { Standard Deviation }) /(\text { Lake Area Mean })
$$

We can make a query to find out the lakes with $C V$ in some range, while still maintaining the shape characteristic, i.e., the average similarity metric between each pair of its shapes is less than a specific value. Fig. 12 shows some of the lakes with $C V=[10 \%, 20 \%]$ and $L_{2 \max }=0.6$ in 1986 .

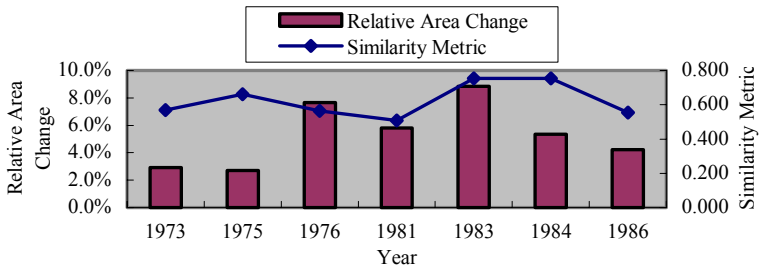

Fig. 10. Interannual shape and surface-area fluctuations.

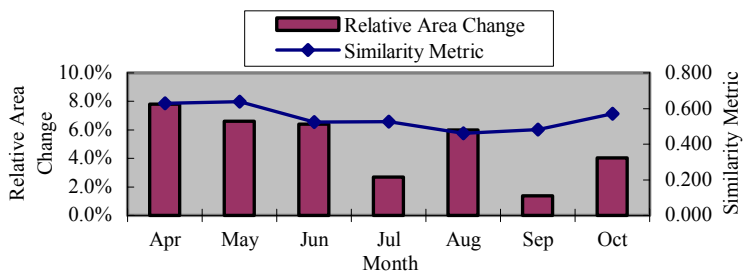

Fig. 11. Seasonal variability of shape and surface-area.

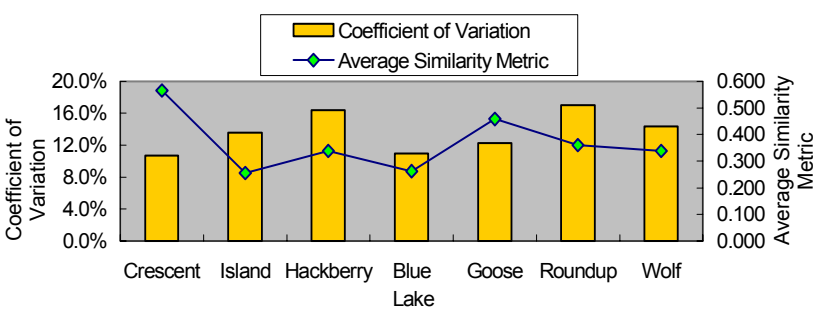

Fig. 12. Lakes with $C V$ between $[10 \%, 20 \%]$ and $L_{2 \max }=0.6$ in 1986 .

\section{SUMMARY}

The results show the effectiveness of shape-based change detection approach in the remote sensing image information mining application, given that the shapes are well retrieved and represented. Our future work will consider trend analysis using time series remotely sensed images with a higher spatial resolution such as Landsat TM and SPOT for specific applications such as the flood or drought monitoring.

\section{ACKNOWLEDGMENTS}

This study is supported by the Nebraska Research Initiative. The authors are thankful to Professor Donald C. Rundquist at UNL for providing the data sets.

\section{REFERENCES}

[1] R. C. Veltkamp and M. Hagedoorn, "State-of-the-art in shape matching," Technical Report UU-CS-1999-27, Utrecht University, Netherlands, 1999.

[2] L. F. Costa, R.M. Cesar, Shape Analysis and Classification: Theory and Practice, CRC Press: Boca Raton, 2001.

[3] P. Revesz, Introduction to Constraint Databases, Springer: Telos, 2001.

[4] E. M. Arkin, L. P. Chew, D. P. Huttenlocher, K. Kedem, and J. S. B. Mitchell, "An efficiently computable metric for comparing polygonal shapes," IEEE Trans. Pattern Anal. Mach. Intell., vol. 13, no. 3, pp. 209-216, March 1991.

[5] C. Chang and C. Lin, "LIBSVM: a library for support vector machines," 2001. Software available at http://www.csie.ntu.edu.tw/ cjlin/libsvm.

[6] A. Cumani, "Edge detection in multispectral images, " CVGIP: Graphical Models and Image Processing, vol. 53, pp. 40-51, January 1991.

[7] D. C. Gosselin, D. C. Rundquist, and S. K. McFeeters, "Remote monitoring of selected ground-water dominated lakes in the Nebraska Sand Hills, "Journal of American Water Resource Association, vol. 36, no. 5, pp. 1039-1051, October 2000. 